\title{
Impact Response of Quasi-Isotropic Asymmetric Carbon Fabric/Epoxy Laminate Infused with MWCNTs
}

\author{
Nand Kishore Singh, Prashant Rawat, and K. K. Singh \\ Department of Mechanical Engineering, Indian School of Mines (ISM), Dhanbad 826004, India \\ Correspondence should be addressed to Nand Kishore Singh; incredablespace@gmail.com
}

Received 8 March 2016; Revised 24 June 2016; Accepted 14 July 2016

Academic Editor: Wei Zhou

Copyright ( 2016 Nand Kishore Singh et al. This is an open access article distributed under the Creative Commons Attribution License, which permits unrestricted use, distribution, and reproduction in any medium, provided the original work is properly cited.

\begin{abstract}
Effect of embedding multiwalled carbon nanotubes (MWCNTs) on low velocity impact response of quasi-isotropic asymmetric laminate of plain woven carbon fabric/epoxy was investigated. Laminates were embedded with $0 \mathrm{wt} . \%, 2 \mathrm{wt} . \%$, and $5 \mathrm{wt} . \% \mathrm{MWCNTs}$ to improve impact resistance. Impact in laminates was conducted according to ASTM D7136 standard at an impact energy of $94.14 \mathrm{~J}$ corresponding to the impact velocity of $6 \mathrm{~m} / \mathrm{sec}$. Energy-time response, force-time response, and pyramidal damage area of laminates doped with varying weight percentage (wt.\%) of MWCNTs were quantified and compared with laminate without MWCNTs. Absorbed impact energy increases by $13.53 \%$ on doping of 2 wt.\% MWCNTs, whereas it decreases by $10.49 \%$ on doping 5 wt.\% MWCNTs. Damage area is reduced on doping 2 wt.\% MWCNTs in laminate.
\end{abstract}

\section{Introduction}

The properties like high strength, high stiffness, and low density have increased the demand of fiber reinforced polymer (FRP) composites. FRP composites have emerged as an alternative to traditional engineering materials and have wide scale application in aerospace, militaries, and automobiles sectors. However, high damage susceptibility of FRPs towards impact because of weak interface between plies is a concern for the application of FRPs. Weak interface causes delamination and matrix crack age leading to fiber failure. Therefore, many researchers have reported various modifications (design, hybrid combination, carbon nanotubes doping, etc.) in order to enhance the impact resistance of FRP laminates.

Karakuzu et al. [1] and Menna et al. [2] used GFRP laminates of different layup to analyze their impact characterization by simulating finite element models. Sevkat et al. [3] investigated the low velocity impact response of plain woven hybrid glass-graphite toughened epoxy composite. The stacking sequences of hybrid composite are glass fabric skin with graphite fabric as core and graphite fabric skin with glass fabric core. Gopinath et al. [4] emphasized two opposing influence of matrix on ballistic performance of the armor. Matrix engages more yarns and prevents their relative sliding which improves ballistic performance. On the contrary to this, it also reduces flexibility and interaction among various layers which reduces ballistic performance. Jiang and Shu [5] investigate the effect of internal sheet involved in two-layer sandwich composites, subjected to low velocity impact. Ghasemnejad et al. [6] fabricated hybrid composite beam by using glass/epoxy and carbon/epoxy composite. For improving impact response, hybrid composite beams were pinned by natural flax yarns before curing process. Addition of flax $z$-pinning leads to improvement in impact resistance because it arrests the crack propagation. N. K. Singh and K. K. Singh [7] and Agarwal et al. [8] had done review on FRP (fiber reinforced polymer) laminates impacted by different type of impactor with varying velocity at different impact locations. Effect of boundary conditions, core type, and transverse reinforcement were also analyzed. Allaoui et al. [9] synthesized composite of MWCNTs and epoxy by varying weight percentage of MWCNTs. Double and quadruple increase in Young's modulus and yield strength was observed on addition of 1 wt.\% and 4 wt.\% MWCNTs. Transition of composite from insulator to conductor was observed by addition of $0.5 \mathrm{wt} . \%$ to $1 \mathrm{wt} . \%$ of MWCNTs. Ci and Bai [10] studied the reinforcement role of carbon nanotubes (CNTs) in epoxy composites with different matrix stiffness. In soft and ductile matrix, 
CNTs as reinforcement shows significant effect. In stiff matrix, CNTs have weak interfacial interaction with matrix which is attributed to complete cross-linking of polymer molecules in stiff matrix. Hence, contributions of CNTs as reinforcement to the mechanical properties of composite are better for soft matrix. Tsantzalis et al. [11] investigated the improvement of toughness of CFRPs having resin doped with carbon nanofibers (CNF) and piezoelectric (PZT) particles. On mixing $1 \mathrm{wt} . \%$ of CNF in matrix, increase of $100 \%$ in fracture energy was observed which is attributed to extensive fiber bridging shown by CNF at fracture surface. On the other hand, doping of PZT particles reduces the fracture toughness because of brittle nature of impregnated particles. Lau et al. [12] investigated micromechanical properties and morphology of fracture surfaces of carbon nanotube composites pretreated at different temperature. Flexural strength of composite beam decreases by $10 \%$ on addition of $2 \mathrm{wt} . \%$ nanotubes. With temperature fracture surface shows variation, at $70^{\circ} \mathrm{C}$ fracture surfaces were perpendicular to nanotubes where as at $-180^{\circ} \mathrm{C}$ fracture surfaces were parallel to nanotubes. This signifies shift of material nature from tougher to brittle with decrease in temperature. Kim et al. [13] investigated the flexural and wears behavior of carbon fabric/epoxy composite and carbon fabric/epoxy composite upgraded by 2 wt.\% acids and saline treated MWCNTs. MWCNTs doped composite shows greater flexural modulus and strength than those of carbon/epoxy composite. Among the two MWCNTs doped composites, saline treated composite showed $10 \%$ and $15 \%$ greater flexural modulus and strength. Even the wear properties of saline treated composite were superior than acid treated composite. Soliman et al. [14] analyzed the effect of mixing $0.5 \mathrm{wt} . \%, 1 \mathrm{wt} . \%$, and $1.5 \mathrm{wt} . \%$ functionalized MWCNTs in laminate of carbon woven fabric/epoxy. The addition of $1.5 \mathrm{wt} . \%$ MWCNTs increases the energy absorption and limits the damage size of carbon woven composites. Taraghi et al. [15] investigated impact response of woven Kevlar/epoxy laminate enriched with MWCNTs at ambient and low temperature $\left(-40^{\circ} \mathrm{C}\right)$. At ambient temperature addition of $0.5 \mathrm{wt} . \%$ MWCNTs leads to $35 \%$ increase in energy absorption while at low temperature $\left(-40^{\circ} \mathrm{C}\right)$ energy absorption increases by $34 \%$ on addition of $0.3 \mathrm{wt} . \%$ MWCNTs. Siegfried et al. [16] and Kostopoulos et al. [17] have done similar investigation on impact and after-impact properties of carbon fiber reinforced composites modified by multiwall carbon nanotubes (MWCNTs). The compression after impact (CAI) modulus increases by $15 \%$ on addition of MWCNTs and the laminate was able to withstand higher compressive stress with less deflection. The CAI strength of MWCNTs doped CFRPs shows increase of around 12-15\% for different impact energy. Tehrani et al. [18] showed increase in tensile failure strain and absorbed impact energy of CFRP on addition of MWCNTs, while its tensile modulus and strength remained almost unaffected. Warrier et al. [19] fabricated glass fiber epoxy composites upgraded by CNTs in three different ways:

(1) Composite fabricated by fiber sized by CNTs and neat epoxy.
(2) Composite of neat fiber and CNTs doped epoxy.

(3) Composite having fibers sized by CNTs and epoxy doped with CNTs.

Composite of sized fiber and neat epoxy showed maximum increase in glass transition temperature, coefficient of thermal expansion (transversely), and fracture toughness. Rahman et al. [20] analyzed the ballistic impact response of E-glass/epoxy composites treated by $0.3 \mathrm{wt} . \%$ and $0.5 \mathrm{wt} . \%$ of amino-functionalized multiwall carbon nanotubes $\left(\mathrm{NH}_{2}-\right.$ MWCNTs). An increase of $6 \%$ in ballistic limit velocity was observed on mixing 0.3 wt. $\%$ of $\mathrm{NH}_{2}$-MWCNTs.

Exceptionally low density, high strength, and high hardness of carbon nanotubes (CNTs) make them potential structural element for reinforcement. Many researchers have shown that addition of carbon nanotubes to laminates advances their impact resistance. In this proposed investigation, quasi-isotropic asymmetric laminate of plain woven carbon fabric of $12 \mathrm{~K} 800$ TEX 600 GSM supplied by CFW Enterprises (Delhi, India) and epoxy reinforced with $0 \mathrm{wt} . \%$, $2 \mathrm{wt} . \%$, and $5 \mathrm{wt} . \%$ MWCNTs of resins were impacted and analyzed at impact energy of $94.14 \mathrm{~J}$. Results show that addition of MWCNTs in epoxy maximizes the impact resistance if weight percentage of mixed MWCNTs is optimum.

\section{Specimen Preparation}

Quasi-isotropic asymmetric laminates of CFRP were fabricated by two types of layers:

(i) Plain woven carbon fabric having weft and warp in $+45^{\circ}$ and $-45^{\circ}$ direction- $(+45,-45)$.

(ii) Plain woven carbon fabric having weft and warp in $0^{\circ}$ and $90^{\circ}$ direction- $(0,90)$.

The stacking sequence of quasi-isotropic asymmetric CFRP laminate is [21]

$$
\begin{aligned}
& {[(0,90) /(+45,-45) /(+45,-45) /(0,90) / /(+45,-45) /} \\
& (0,90) /(0,90) /(+45,-45)] .
\end{aligned}
$$

The stiffness matrixes of laminates are [21] as follows:

(1) Bending-extension coupling matrix, $[B]=0$.

(2) Extension stiffness matrix, $[A]$

$$
A_{i j}=4 t\left\{\left(\overline{Q_{i j}}\right)_{\phi}+\left(\overline{Q_{i j}}\right)_{\theta}\right\} .
$$

(3) Bending stiffness matrix, $[D]$

$$
D_{i j}=\frac{64}{3} t^{3}\left\{\left(Q_{i j}\right)_{\phi}+\left(Q_{i j}\right)_{\theta}\right\} .
$$

Based on the above stacking sequence CFRP laminates with and without MWCNTs are fabricated by impregnating carbon fabric with epoxy enriched with MWCNTs and pure epoxy, respectively. Liquid epoxy resin $\left(4,4^{\prime}\right.$-Isopropylidenediphenol, oligomeric reaction products with 1-chloro-2,3epoxypropane) and hardener (K6) manufactured by Atul 


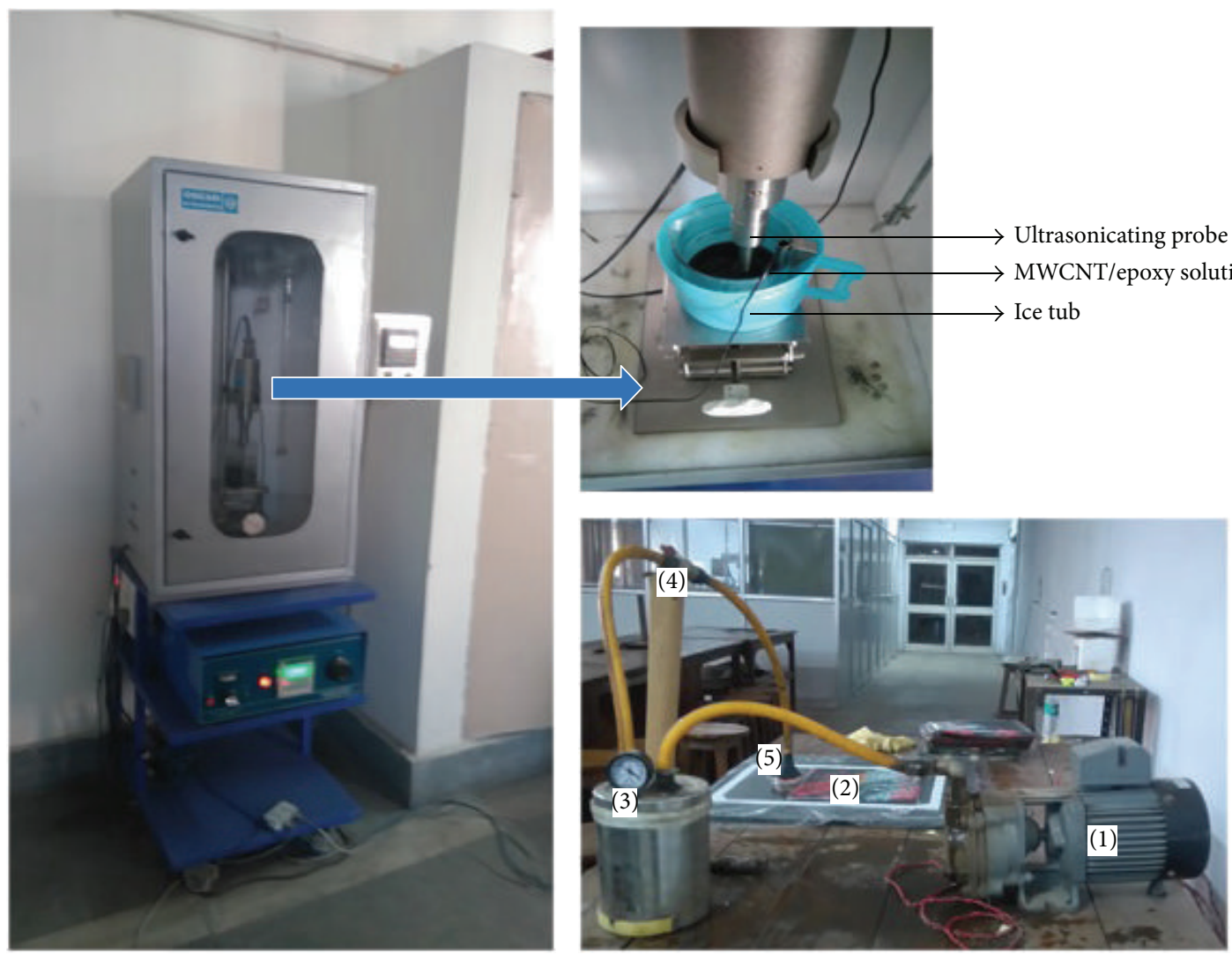
(1) Vacuum pump
(2) Vacuum bag
(3) Pressure gauge
(4) Opening valve
(5) Nozzle

(a)

(b)

Figure 1: (a) Probe Ultrasonicator (Oscar Ultrasonics Pvt. Ltd. Specification: Power Input 230 V 50 Hz, 4 Amps). (b) Setup of vacuum bagging method used for fabrication of laminates.

Ltd., Valsad, Gujarat, India, were used for fabrication of laminates. Multiwall carbon nanotubes were supplied by United Nanotech Innovations Pvt. Ltd. (Bangalore, India). Length and thickness of MWCNTs were ranging from 1 to 10 microns and 5 to $20 \mathrm{~nm}$, respectively, with $98 \%$ of purity. Laminates with 0 wt. $\%$ MWCNTs were fabricated by impregnating carbon fabric by solution of epoxy and hardener mixed in mass ratio of $10: 1$. Whereas laminates doped with MWCNTs were fabricated by wetting carbon fabric with modified matrix. In order to modify matrix properties multiwall carbon nanotubes were mixed in epoxy by using probe ultrasonicator for avoiding excessive heat build-up MWCNT/epoxy solution was kept in ice tub (Figure 1(a)). After $1 \mathrm{hr}$ of ultrasonicating hardener was mixed using hand stirrer at $950 \mathrm{rpm}$ for 10 minutes. This two-phased MWCNT/resins solution was used to impregnate carbon fabric for fabricating MWCNTs doped laminates. Laminates with or without MWCNTs were fabricated by hand layup method followed by vacuum bagging method as shown in Figure 1(b).

\section{Experimental Setup}

The specimen used for conducting drop weight impact test, on Instron-CEAST 9350 (Figure 2) by following ASTM D7136, had dimension of $100 \mathrm{~mm} \times 100 \mathrm{~mm} \times(3.9 \pm 0.2) \mathrm{mm}$. Square specimen was rigidly clamped in a frame leaving central unsupported area of $1256 \mathrm{~mm}^{2}$ for impact. Hemispherical headed impactor of diameter $20 \mathrm{~mm}$ was impacted at impact energy of $94.14 \mathrm{~J}$ corresponding to an impact velocity of $6 \mathrm{~m} / \mathrm{sec}$. Three samples of each type of specimen were impacted for the reliability of results.

\section{Result and Discussion}

4.1. Energy-Time Response. Impact of $94.14 \mathrm{~J}$ by impactor causes fiber breakage in quasi-isotropic asymmetric laminate of CFRP with and without MWCNTs. Energy absorbed by asymmetric CFRP laminate without MWCNTs was $57.39 \mathrm{~J}$, which increases to $65.16 \mathrm{~J}$ on embedment of $2 \mathrm{wt} . \%$ MWCNTs 


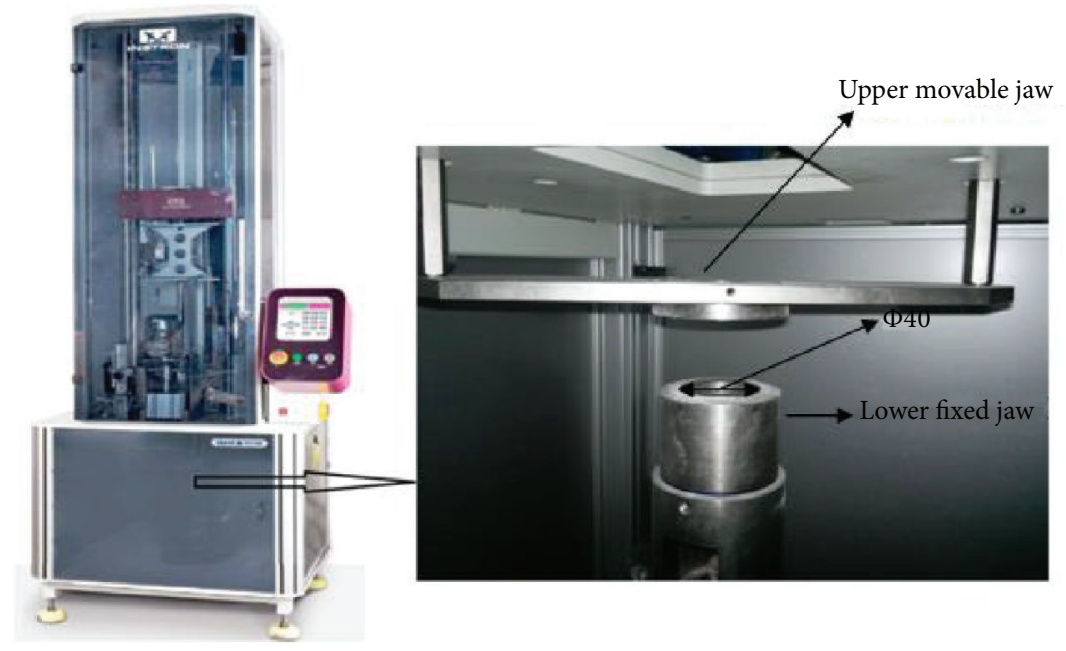

Figure 2: Drop Tower Impact Tester, Instron-CEAST 9350.

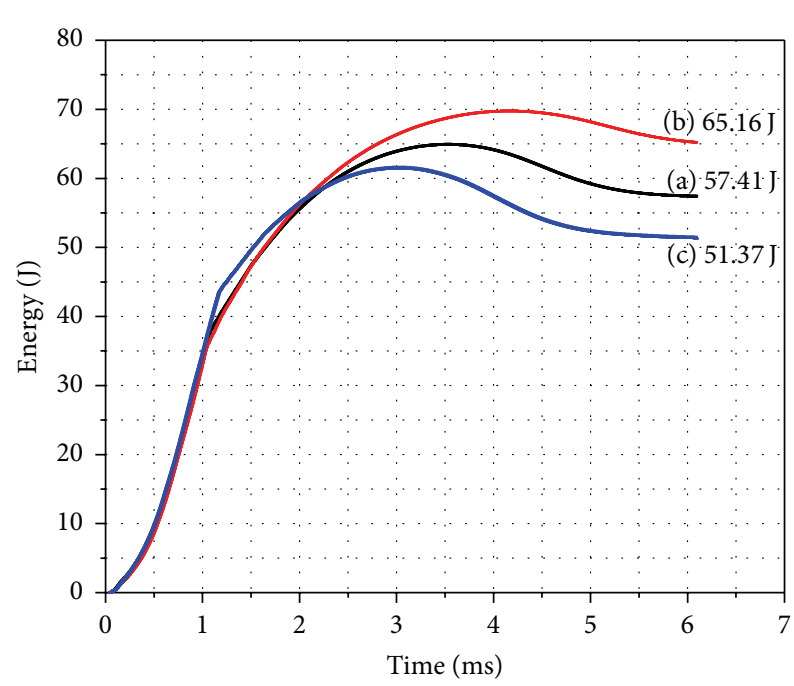

(a) Asymmetric CFRP laminate with $0 \mathrm{wt} \%$ MWCNTs

- (b) Asymmetric CFRP laminate with $2 \mathrm{wt} \%$ MWCNTs

- (c) Asymmetric CFRP laminate with $5 \mathrm{wt} \%$ MWCNTs

FIgURE 3: Energy-time relation of asymmetric CFRP laminate embedded with 0 wt.\%, 2 wt.\%, and 5 wt.\% MWCNTs.

as shown in Figure 3. On the contrary, addition of $5 \mathrm{wt} . \%$ MWCNTs reduces energy absorption to $51.37 \mathrm{~J}$ (shown in Figure 3).

The reduction of $10.49 \%$ in energy absorption is attributed to formation of viscous mixture of epoxy by adding $5 \mathrm{wt} . \%$ MWCNTs, which does not impregnate/wet fibers resulting in weak interfacial bond between fiber and matrix as shown in Figure 4. These improper wetting also leads to creation of voids and crack initiative points in the laminate. On mixing 2 wt.\% MWCNTs energy absorption of laminate was increased by $13.53 \%$. This increase was observed because mixture of epoxy and $2 \mathrm{wt} . \%$ MWCNTs wets/impregnates fibers as good as pure epoxy in case of laminate without MWCNTs (shown in Figure 4), and availability of randomly oriented MWCNTs in matrix provides additional reinforcement in all direction which act as bridging agent and prevent propagation of cracks.

4.2. Force-Time Response. Fibers in fiber reinforced laminate bear the maximum load; therefore, doping of MWCNTs in matrix does not bring significant improvement in load carrying capacity of laminates. Maximum load carrying capacity of used asymmetric CFRP laminates embedded with 0 wt.\%, $2 \mathrm{wt} . \%$, and $5 \mathrm{wt} . \%$ MWCNTs is $15.86 \mathrm{KN}, 17.26 \mathrm{KN}$, and $18.43 \mathrm{KN}$, respectively. The marginal improvement of $1.4 \mathrm{KN}$ and $2.6 \mathrm{KN}$ in load carrying capacity of laminates doped with 2 wt.\% and 5 wt.\% MWCNTs, respectively, is attributed to the extra load carried by MWCNTs doped as reinforcement in matrix. As shown in Figure 4, nature of force-time relation is same for laminate having $0 \mathrm{wt} . \%, 2 \mathrm{wt} . \%$, and $5 \mathrm{wt} . \%$ MWCNTs. In the beginning force increases slowly, which is the result of an oscillation of the laminate after first contact of impactor. When the laminate moves back upward the force increases steeply to its maximum value. After peak value there is sudden drop in force signifying commencement of fiber breakage, and then several small valleys and peak signify redistribution (unloading and reloading) of force after breakage of each fiber (Figure 5).

4.3. Damage Evolution. As shown in Figure 6, typical failure pattern of asymmetric CFRP laminate with ( $2 \mathrm{wt} . \%$ and 5 wt.\%) and without MWCNTs is pyramidal in structure. This pyramidal fracture is attributed to the plain woven carbon fabric used in fabrication of laminates. The height and width of pyramidal damage quantify the laminate fracture which involves fiber and matrix failure. As shown in Figures 7, 8, and 9, the height of pyramidal damage is $9 \mathrm{~mm}, 5 \mathrm{~mm}$, and $11 \mathrm{~mm}$ for laminates embedded with 0 wt.\%, 2 wt. $\%$, and 5 wt. $\%$ MWCNTs, respectively. Similarly, the width of pyramidal damage is $25.8 \mathrm{~mm}, 19.6 \mathrm{~mm}$, and $28.9 \mathrm{~mm}$ for laminate with 0 wt. $\%, 2$ wt. $\%$, and 5 wt. $\%$ MWCNTs, respectively.

As shown in Figure 8 the size of damage on addition of $2 \mathrm{wt} \%$ MWCNTs is small in comparison with neat epoxy 


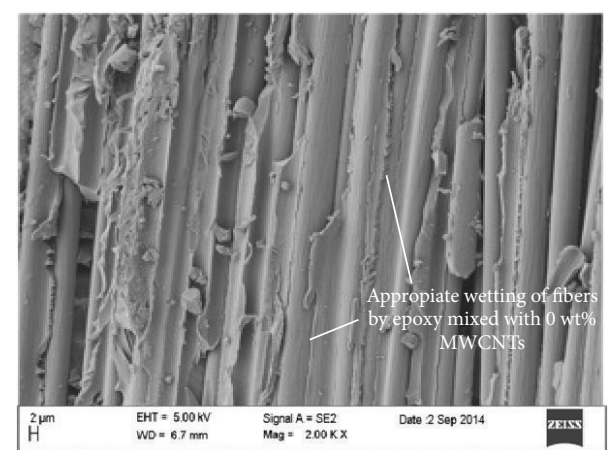

(a)

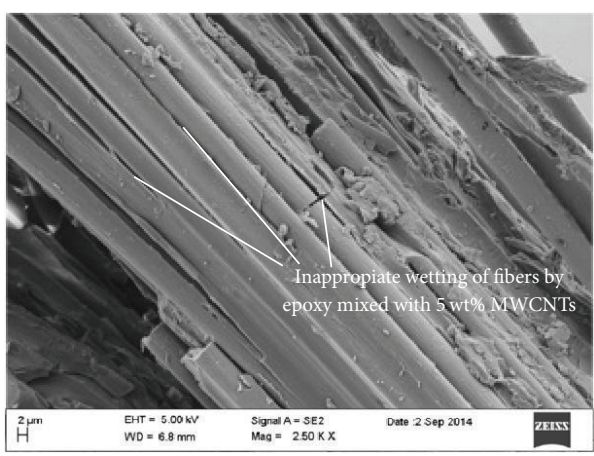

(c)

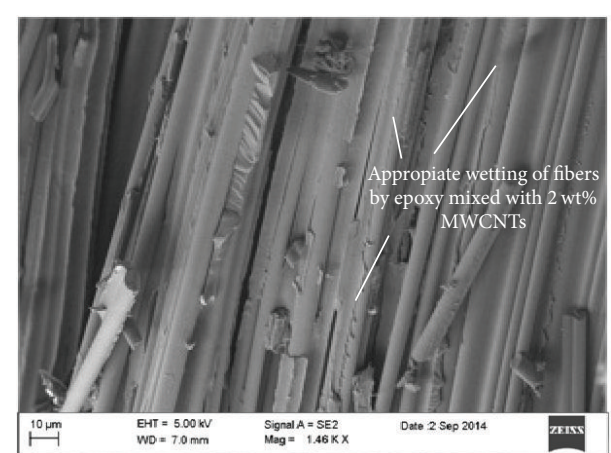

(b)

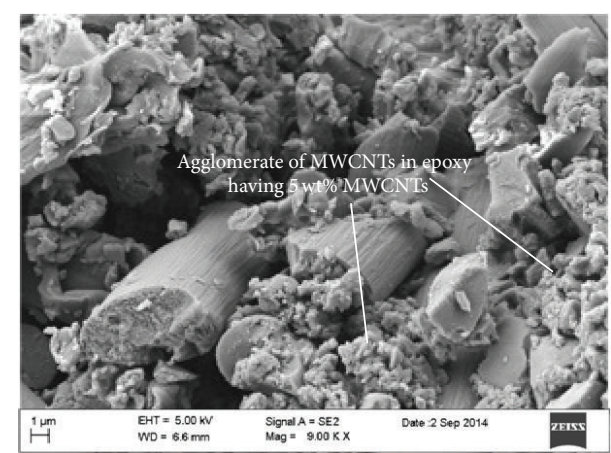

(d)

Figure 4: FE-SEM image of interface of fiber and epoxy mixed with (a) 0 wt.\% MWCNTs, (b) 2 wt.\% MWCNTs, (c) and 5 wt.\% MWCNTs and (d) showing agglomeration of MWCNTs in laminate having $5 \mathrm{wt} . \%$ MWCNTs in epoxy.

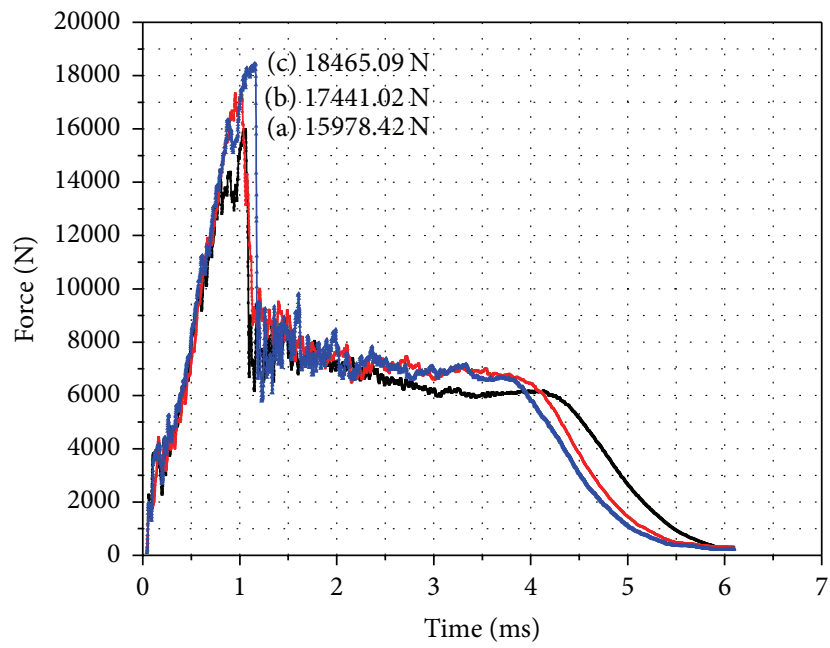

- (a) Asymmetric CFRP laminate doped with $0 \mathrm{wt} \%$ MWCNTs

- (b) Asymmetric CFRP laminate doped with $2 \mathrm{wt} \%$ MWCNTs

- (c) Asymmetric CFRP laminate doped with $5 \mathrm{wt} \%$ MWCNTs

FIGURE 5: Force-time relations of asymmetric CFRP laminate embedded with 0 wt.\%, 2 wt.\%, and 5 wt. $\%$ MWCNTs.

composite. This is attributed to interaction between MWCNTs and matrix that arrests the development of damage by bridging around the crack in impacted area. On the contrary, the size of damage on addition of $5 \mathrm{wt} . \%$ MWCNTs

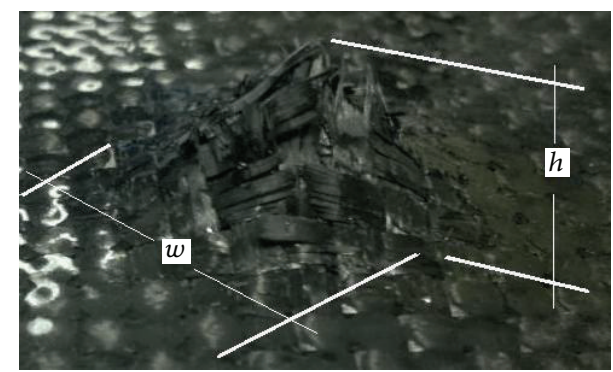

Figure 6: Pyramidal damage pattern of woven carbon fabric composite.

is larger than the damage of laminate with $0 \mathrm{wt} . \%$ MWCNTs. Addition of $5 \mathrm{wt} . \%$ MWCNTs forms viscous solution of epoxy and leads to agglomeration of MWCNTs (shown in Figure 4(d)). This viscous solution and MWCNTs agglomerate lead to weak matrix-fiber and matrix-MWCNTs interface, respectively, which reduces bridging action leading to larger damage region in comparison to laminate with neat ( $0 \mathrm{wt} . \%$ MWCNTs) epoxy.

\section{Conclusion}

In this experimental study, low velocity impact response of quasi-isotropic asymmetric CFRP laminates embedded with MWCNTs was analyzed. Epoxy was doped with 0 wt.\%, 


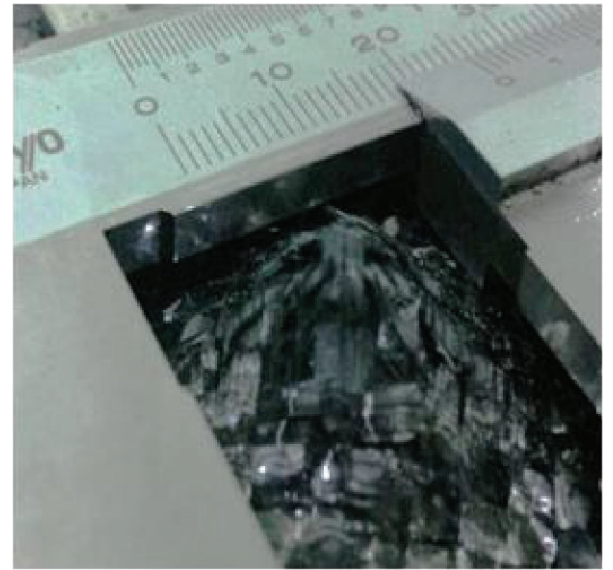

Width, $w_{0 \mathrm{wt} . \% \text { MWCNTs }}=25.8 \mathrm{~mm}$

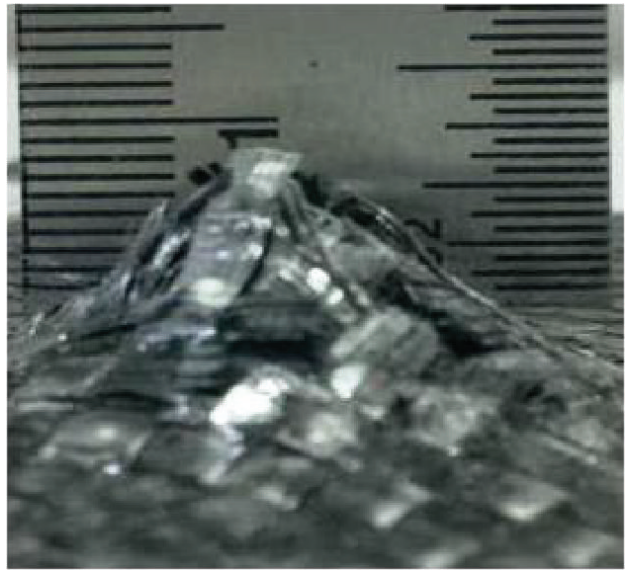

Height, $h_{0 \text { wt. } \% \text { MWCNTs }}=9 \mathrm{~mm}$

FIgURE 7: Pyramidal damage of asymmetric CFRP with 0 wt.\% MWCNTs mixed in epoxy.

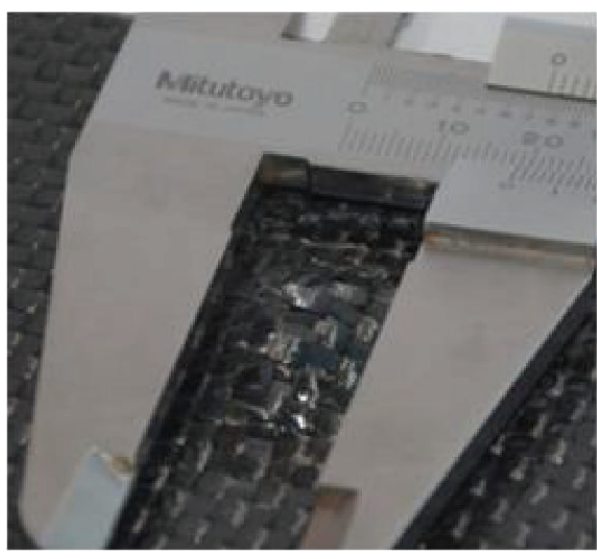

Width, $w_{2 \text { wt. } \% \text { MWCNTs }}=19.6 \mathrm{~mm}$

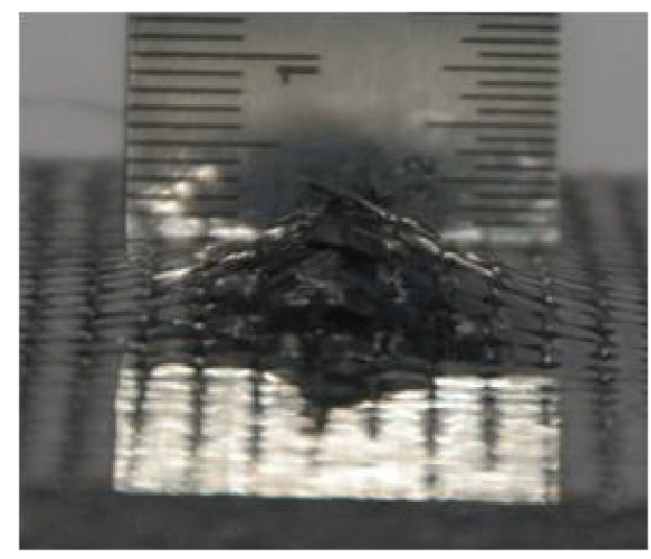

Height, $h_{2 \text { wt. } \% \text { MWCNTs }}=5 \mathrm{~mm}$

Figure 8: Pyramidal damage of asymmetric CFRP with 2 wt.\% MWCNTs mixed in epoxy.

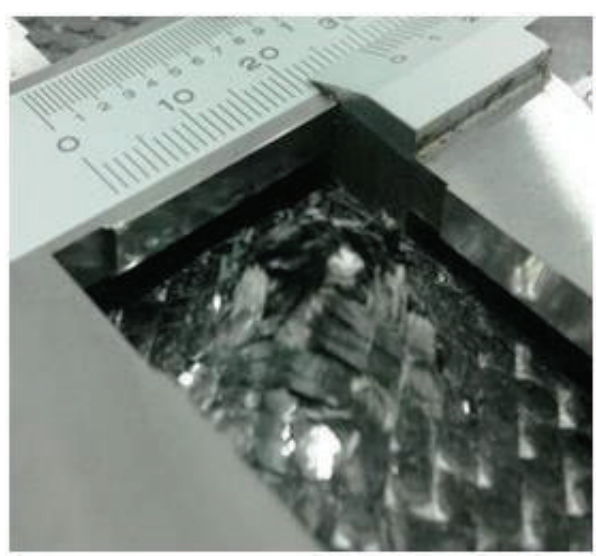

Width, $w_{5 \text { wt. } \% \text { MWCNTs }}=28.9 \mathrm{~mm}$

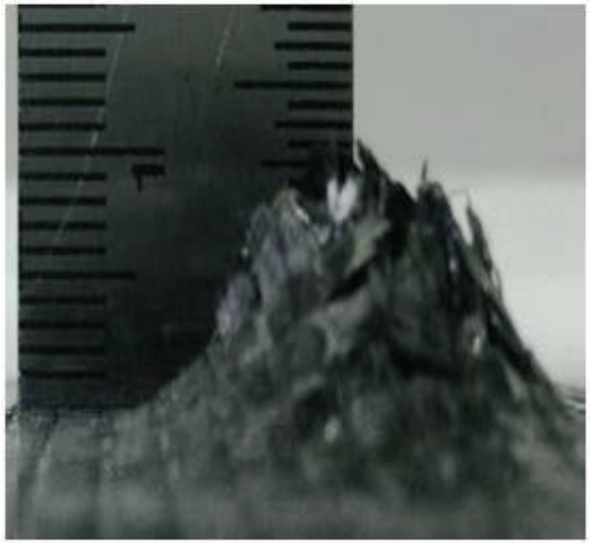

Height, $h_{5 \mathrm{wt} . \% \mathrm{MWCNTs}}=11 \mathrm{~mm}$

FIGURE 9: Pyramidal damage of asymmetric CFRP with 5 wt.\% MWCNTs mixed in epoxy. 
$2 \mathrm{wt.} \%$, and $5 \mathrm{wt} . \%$ MWCNTs for making MWCNTs enriched laminates. The significant outcomes of the present study are as follows:

(i) Laminate with pure epoxy (0wt.\% MWCNTs) absorbs impact energy of $57.39 \mathrm{~J}$, which increases to $65.16 \mathrm{~J}$ (by $13.53 \%$ ) on addition of 2 wt.\% MWCNTs. On the contrary, absorbed energy decreases to $51.37 \mathrm{~J}$ (by $10.49 \%$ ) on addition of $5 \mathrm{wt} . \%$ MWCNTs.

(ii) Effect of epoxy upgradation (by mixing of MWCNTs) on load carrying capacity was insignificant, which is attributed to the fact that fibers govern the load carrying capacity of composites. Load carrying capacity of laminate with epoxy having $0 \mathrm{wt} . \%$, $2 \mathrm{wt} . \%$, and $5 \mathrm{wt} . \%$ MWCNTs was $15.86 \mathrm{KN}, 17.26 \mathrm{KN}$, and $18.43 \mathrm{KN}$, respectively.

(iii) On doping 2 wt.\% MWCNTs size of pyramidal damage in laminate is least in comparison with laminates doped with 0 wt. $\%$ and 5 wt. $\%$ MWCNTs. This is attributed to the bridging action of MWCNTs around cracks in laminates having epoxy embedded with 2 wt.\% MWCNTs, whereas agglomeration of MWCNTs in laminate having epoxy mixed with 5 wt. $\%$ of MWCNTs prevents the bridging action and accelerated the crack propagation by providing voids.

\section{Competing Interests}

The authors declare that they have no competing interests.

\section{References}

[1] R. Karakuzu, E. Erbil, and M. Aktas, "Impact characterization of glass/epoxy composite plates: an experimental and numerical study," Composites-Part B: Engineering, vol. 41, no. 5, pp. 388395, 2010.

[2] C. Menna, D. Asprone, G. Caprino, V. Lopresto, and A. Prota, "Numerical simulation of impact tests on GFRP composite laminates," International Journal of Impact Engineering, vol. 38, no. 8-9, pp. 677-685, 2011.

[3] E. Sevkat, B. Liaw, F. Delale, and B. B. Raju, "Drop-weight impact of plain-woven hybrid glass-graphite/toughened epoxy composites," Composites Part A: Applied Science and Manufacturing, vol. 40, no. 8, pp. 1090-1110, 2009.

[4] G. Gopinath, J. Q. Zheng, and R. C. Batra, "Effect of matrix on ballistic performance of soft body armor," Composite Structures, vol. 94, no. 9, pp. 2690-2696, 2012.

[5] D. Jiang and D. Shu, "Local displacement of core in twolayer sandwich composite structures subjected to low velocity impact," Composite Structures, vol. 71, no. 1, pp. 53-60, 2005.

[6] H. Ghasemnejad, V. R. Soroush, P. J. Mason, and B. Weager, "To improve impact damage response of single and multidelaminated FRP composites using natural Flax yarn," Materials \& Design, vol. 36, pp. 865-873, 2012.

[7] N. K. Singh and K. K. Singh, "Review on impact analysis of FRP composites validated by LS-DYNA," Polymer Composites, vol. 36, no. 10, pp. 1786-1798, 2015.

[8] S. Agarwal, K. K. Singh, and P. K. Sarkar, "Impact damage on fibre-reinforced polymer matrix composite-a review," Journal of Composite Materials, vol. 48, no. 3, pp. 317-332, 2012.
[9] A. Allaoui, S. Bai, H. M. Cheng, and J. B. Bai, "Mechanical and electrical properties of a MWNT/epoxy composite," Composites Science and Technology, vol. 62, no. 15, pp. 1993-1998, 2002.

[10] L. Ci and J. Bai, "The reinforcement role of carbon nanotubes in epoxy composites with different matrix stiffness," Composites Science and Technology, vol. 66, no. 3-4, pp. 599-603, 2006.

[11] S. Tsantzalis, P. Karapappas, A. Vavouliotis et al., "On the improvement of toughness of CFRPs with resin doped with CNF and PZT particles," Composites Part A: Applied Science and Manufacturing, vol. 38, no. 4, pp. 1159-1162, 2007.

[12] K.-T. Lau, S.-Q. Shi, and H.-M. Cheng, "Micro-mechanical properties and morphological observation on fracture surfaces of carbon nanotube composites pre-treated at different temperatures," Composites Science and Technology, vol. 63, no. 8, pp. 1161-1164, 2003.

[13] M. T. Kim, K. Y. Rhee, J. H. Lee, D. Hui, and A. K. T. Lau, "Property enhancement of a carbon fiber/epoxy composite by using carbon nanotubes," Composites Part B: Engineering, vol. 42, no. 5, pp. 1257-1261, 2011.

[14] E. M. Soliman, M. P. Sheyka, and M. R. Taha, "Low-velocity impact of thin woven carbon fabric composites incorporating multi-walled carbon nanotubes," International Journal of Impact Engineering, vol. 47, pp. 39-47, 2012.

[15] I. Taraghi, A. Fereidoon, and F. Taheri-Behrooz, "Low-velocity impact response of woven Kevlar/epoxy laminated composites reinforced with multi-walled carbon nanotubes at ambient and low temperatures," Materials and Design, vol. 53, pp. 152-158, 2014.

[16] M. Siegfried, C. Tola, M. Claes, S. V. Lomov, I. Verpoest, and L. Gorbatikh, "Impact and residual after impact properties of carbon fiber/epoxy composites modified with carbon nanotubes," Composite Structures, vol. 111, no. 1, pp. 488-496, 2014.

[17] V. Kostopoulos, A. Baltopoulos, P. Karapappas, A. Vavouliotis, and A. Paipetis, "Impact and after-impact properties of carbon fibre reinforced composites enhanced with multi-wall carbon nanotubes," Composites Science and Technology, vol. 70, no. 4, pp. 553-563, 2010.

[18] M. Tehrani, A. Y. Boroujeni, T. B. Hartman, T. P. Haugh, S. W. Case, and M. S. Al-Haik, "Mechanical characterization and impact damage assessment of a woven carbon fiber reinforced carbon nanotube-epoxy composite," Composites Science and Technology, vol. 75, pp. 42-48, 2013.

[19] A. Warrier, A. Godara, O. Rochez et al., "The effect of adding carbon nanotubes to glass/epoxy composites in the fibre sizing and/or the matrix," Composites Part A: Applied Science and Manufacturing, vol. 41, no. 4, pp. 532-538, 2010.

[20] M. Rahman, M. Hosur, S. Zainuddin et al., "Effects of aminofunctionalized MWCNTs on ballistic impact performance of E-glass/epoxy composites using a spherical projectile," International Journal of Impact Engineering, vol. 57, pp. 108-118, 2013.

[21] K. K. Singh, N. K. Singh, and R. Jha, "Analysis of symmetric and asymmetric glass fiber reinforced plastic laminates subjected to low-velocity impact," Journal of Composite Materials, vol. 50, no. 14, pp. 1853-1863, 2016. 

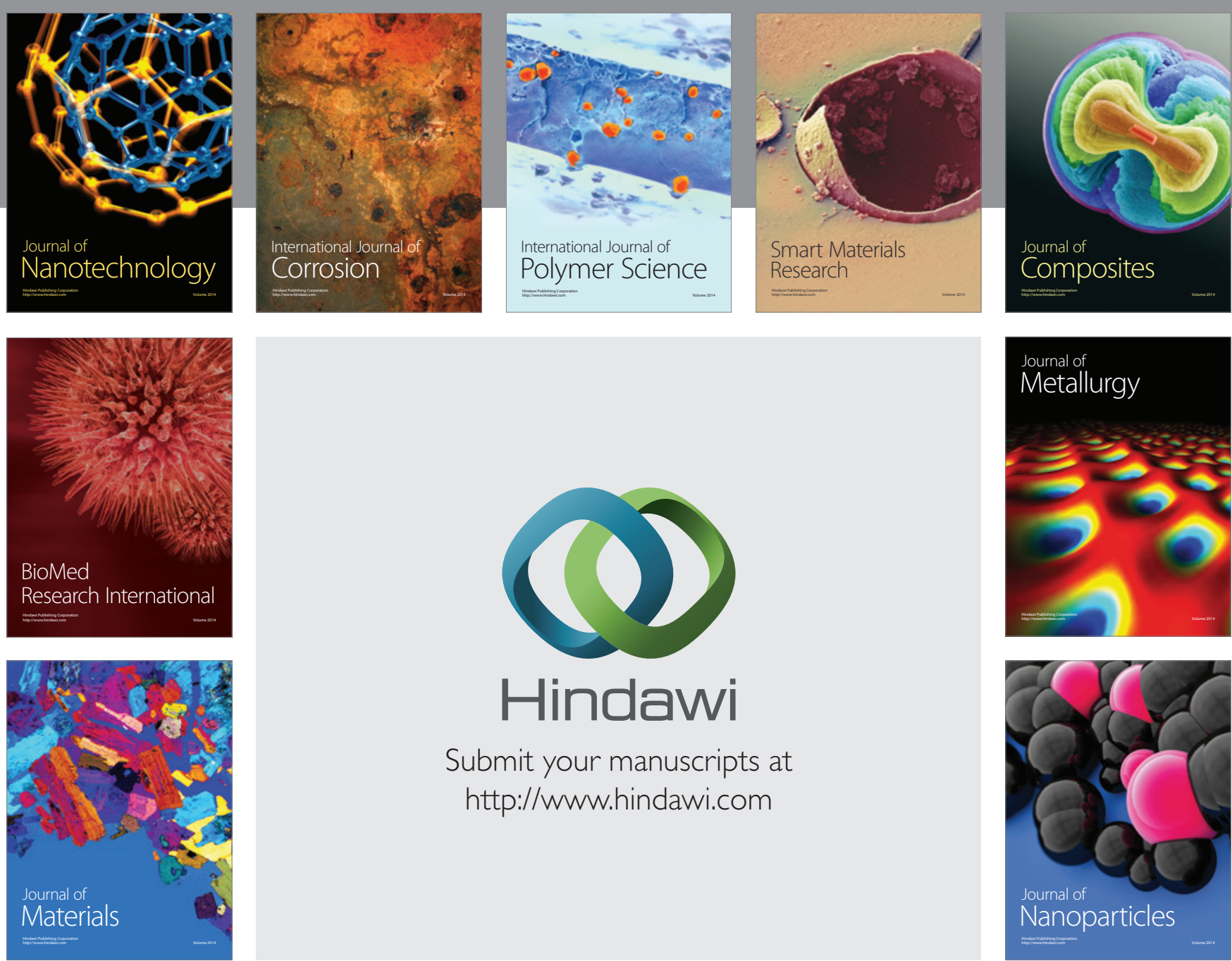

\section{Hindawi}

Submit your manuscripts at

http://www.hindawi.com

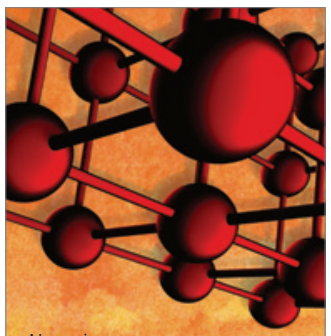

Materials Science and Engineering
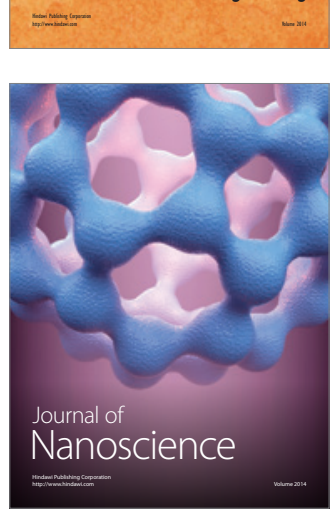
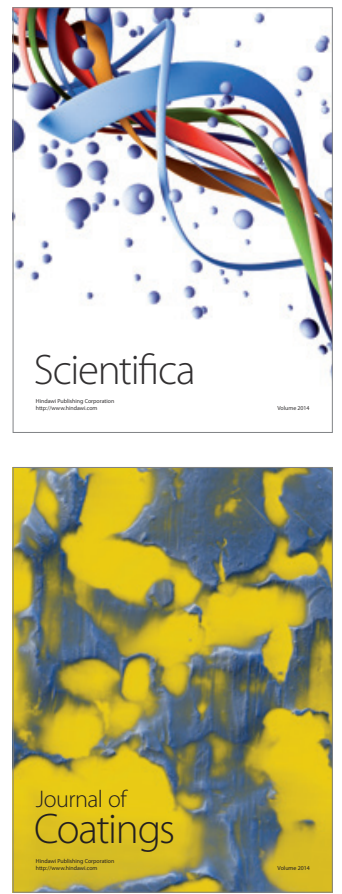
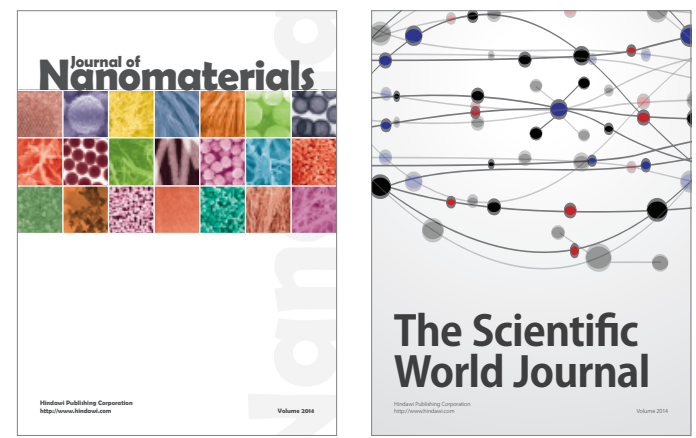

The Scientific World Journal
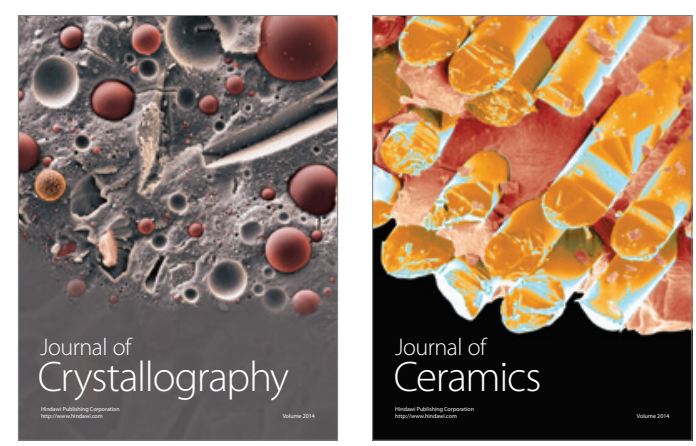
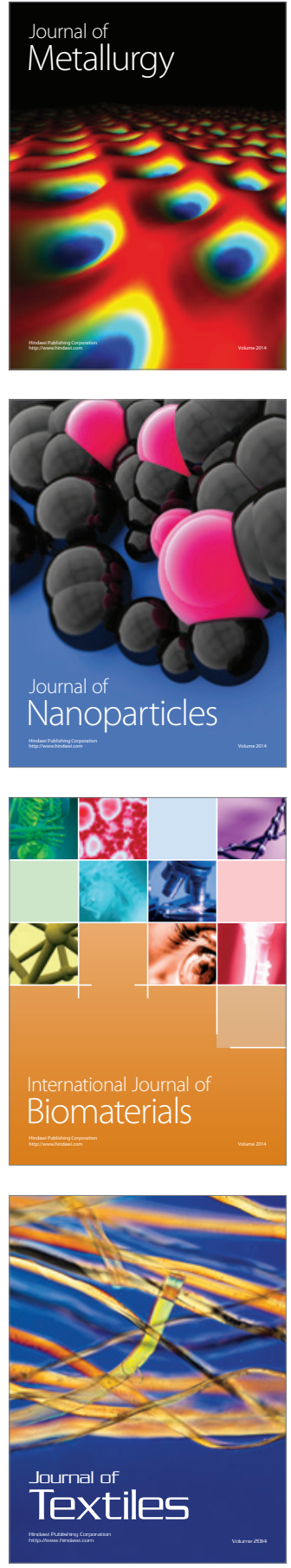